Original Article

\title{
Validity and reliability study of the motor accuracy test in Turkey
}

\author{
Fehime Senem Akbay, MSc ${ }^{1)^{*}}$, Ferda DokuztuĞ Üçsular, PhD ${ }^{1)}$, Tomris Duymaz, PhD²) \\ 1) Department of Physical Therapy and Rehabilitation, Health Science Faculty, Demiroglu Bilim \\ University: Istanbul 34394, Turkey \\ 2) Department of Physical Therapy and Rehabilitation, Health Science Faculty, Istanbul Bilgi \\ University, Turkey
}

\begin{abstract}
Purpose] The aim of this study was to identify the validity and reliability of the Motor Accuracy (MAc-R) test of the Sensory Integration and Praxis Test (SIPT) in Turkey. [Participants and Methods] The study sample group consisted of 100 children at a primary school registered to the Hatay Provincial Directorate of National Education. The children's ages ranged between 6 and 8 years, 11 months. The MAc-R test was implemented on the children through test-retest with a 2 -week interval and whether or not the difference between these results was statistically significant was investigated. In addition, the Frostig Developmental Test of Visual Perception Eye-Hand Coordination Test was implemented once on each child and its relationship with the MAc-R test was examined. [Results] It was concluded that the MAc- $\mathrm{R}$ test is valid $(\mathrm{r}=-0.531)$ and reliable $(\mathrm{r}=0.834)$ in Turkish schoolchildren aged between 6 and 8 years, 11 months. [Conclusion] As a result, it is believed that identifying the validity and reliability of the MAc-R test in Turkey will have an important place in evaluating children's sensory integration in physiotherapy and rehabilitation practices.

Key words: SIPT, Motor accuracy, Validity
\end{abstract}

(This article was submitted Mar. 11, 2019, and was accepted Apr. 22, 2019)

\section{INTRODUCTION}

Sensory Integration and Praxis Test (SIPT) is a standardized testing stream consisting of 17 subtests that enables the evaluation of the tactile, proprioceptive, visual, and vestibular functions and sensory perception of children aged between 4 years, 0 months, and 8 years, 11 months ${ }^{1-3)}$. The test results provided information related to specific sensorimotor functions such as static and dynamic balance, postural-ocular mechanisms, bilateral coordination, lateralization skills, and praxis ${ }^{4}$. It is possible to adjust children's education and contribute to the increase in their academic success by identifying normal, above-normal, and subnormal areas in sensory integration via SIPT. Furthermore, it enables the identification of children with sensory integration problems who are overlooked in schools and includes them in sensory integration training ${ }^{1,5)}$. With its 17 subtests, the SIPT evaluates a child's perception as a whole. When the interactions of all of the subtests are assessed together, all of the aspects of a child's sensory system are evaluated. This holistic approach is one of the important features that distinguish SIPT from other sensory tests ${ }^{1,6)}$.

SIPT's 17 subtests are also used independently to evaluate different sensory areas. It has been reported that when applied alone, the Motor Accuracy (MAc-R) test is the most successful of SIPT's subtests in grouping normal and dysfunctional children ${ }^{1)}$.

The MAc-R test provides information regarding the state of sensory integration when applied alone and can be used in clinics ${ }^{1,5,7,8)}$.

*Corresponding author. Fehime Senem Akbay (E-mail: senemakbay@gmail.com)

(C2019 The Society of Physical Therapy Science. Published by IPEC Inc.

(c) (1) $\odot$ This is an open-access article distributed under the terms of the Creative Commons Attribution Non-Commercial No Derivatives cc) 
The MAc-R test has a wide scope of use for evaluating the sensory integration ${ }^{1,7-14)}$. The MAc-R test evaluates visual area management, vestibular-somatosensory processing, neuromotor coordination, and main somatopraxis bilateral integration skills regarding sensory integration. The MAc-R test does not solely evaluate sensory integration. Eye-hand coordination, ocular tracking, and the use of both hands are required during the test, which also measures praxis, in other words, skills.

The MAc test was created by Ayres in 1964 and revised in 1980 (MAc-R). No changes have been made to the test materials, test purpose, and type of application in both versions; only the scoring method was altered. Both versions of the test were carefully standardized and the validity and reliability were shown ${ }^{1,15,16)}$.

Although the MAc-R test has been applied in Turkey, its validity and reliability have not been confirmed ${ }^{17-21)}$. The aim of this study was to research the MAc-R test's validity and reliability in Turkey.

\section{PARTICIPANTS AND METHODS}

In this study, the MAc-R test's validity and reliability in Turkey was investigated. To identify its reliability, the MAc-R test was implemented on each of the studied children through test-retest with a 2-week interval. To identify the validity of the test, the relationship between the MAc-R test and the Frostig Developmental Test of Visual Perception (DTVP-2) Eye-Hand Coordination Test ${ }^{22-24)}$ was examined.

A total of 87 participants were included in this study with $95 \%$ trust and $80 \%$ power. Considering that there may be prospective information loss, the sampling calculation was identified as at least 100 individuals.

A total of 100 children ( 49 girls and 51 boys) who were randomly selected from 248 students in the first and second grades of a primary school in Antakya/Defne province of Hatay participated in this study between May 24th, 2016, and June 8th, 2016.

The inclusion criteria were as follows: no physical, psychological, or mental disabilities; age between 6 and 8 years, 11 months; and consent provided by both the child and the parents. The exclusion criteria were as follows: having any kind of physical, visual, or hearing disabilities; mental retardation; or possessing a learning disability. Information about whether the children had any physical, mental, or psychological problems was obtained from the school's guidance and counseling center. No child met any of the exclusion criteria, so none were excluded from the study. All of the included children completed all of the test phases.

Approval for the research was obtained from the Istanbul Bilim University Clinical Research Ethics Committee with number 16.02.2016/45-324. Approval required to conduct the study in a primary school in Hatay was obtained from the Hatay Provincial Directorate of National Education and the Governorate of Hatay. To use the MAc-R test's original materials in this study, approval was obtained from Western Psychological Services (WPS) as per the copyright. Prior to the children's inclusion in the study, their parents were informed about the tests and were asked to read and sign the informed volunteer consent form. All of the tests used in this study (the MAc-R test-retest and the DTVP-2 Eye-Hand Coordination Test) were applied and scored by an experienced physiotherapist trained to apply SIPT.

To identify the reliability of SIPT's MAc-R, the MAc-R test was applied to the same group of children twice with a 2-week interval. During the test's application, the test sheet, the protocol sheet, a red pen with a nylon tip, a stopwatch, an adhesive tape, a map measure, and a CD with external storage that contained the computer software were used. The children were expected to draw over the thick black lines with the red pen and not overflow it. The length of the overflow area was measured over the thick black line with the map measure and recorded in inches. When there were no overflows, a score of "0" was awarded. " 0 " was the top score in the evaluation.

Depending on the rate of the divergence from the main line, the overflow length was multiplied from the closest point to the farthest, with scores of 1,2,3, and 4 respectively. The raw score was calculated by adding up the resulting scores. To identify the weighted total accuracy score, the inch value of the length of the area of the overflow was recorded to the computer software via the CD and the external storage. The weighted total accuracy score using U.S. norms and the time factor identified according to these norms were obtained using the computer software. " 0 " described the standard state of the evaluation. The consistency of the raw score (test-retest) and the weighted total accuracy score (test-retest) results were investigated to identify the reliability of the MAc-R test.

The reference-dependent validity (criterion-referenced) of the MAc-R test was investigated in this study. The DTVP-2 was used as the reference test and the Eye-Hand Coordination Test was chosen from it. The relationship between the raw scores of the first application of the MAc-R test and the total scores of the Eye-Hand Coordination Test from the DTVP-2 was investigated. Four eye-hand coordination tests that were present in the application booklet were used in the DTVP-2 evaluation. During the test, the subjects were expected to draw lines toward the targets through the designated lines. The total score was identified according to the amount of overflow from the designated lines and the children lifting their hands while drawing. " 0 " was the worst score and " 186 " was the best.

The reliability evaluation was calculated via the MAc-R's test-retest raw scores and the weighted total accuracy scores. The validity evaluation was conducted using the MAc-R test's raw scores and the DTVP-2 Eye-Hand Coordination Test. The results of the conformity analysis between these two tests were investigated for their validity.

In the evaluations, descriptive statistics were provided with frequency and percentage values for the discrete variables, and with average, standard deviation, median, minimum, and maximum values for the continuous variables. 
Table 1. MAc-R test-retest results

\begin{tabular}{lcc}
\hline \multicolumn{1}{c}{ MAc-R } & Average \pm SD & Median (min-max) \\
\hline Test dominant hand raw score & $43.36 \pm 5.43$ & $42.50(31.50-58.50)$ \\
Retest dominant hand raw score & $44.28 \pm 9.93$ & $42.00(20.50-77.00)$ \\
Test dominant hand time (s) & $117.77 \pm 37.65$ & $113.00(31.00-250.00)$ \\
Retest dominant hand time (s) & $98.95 \pm 37.60$ & $97.50(25.00-260.00)$ \\
Test nondominant hand raw score & $53.05 \pm 13.24$ & $50.75(33.50-124.00)$ \\
Retest nondominant hand raw score & $56.80 \pm 17.65$ & $52.00(30.00-115.50)$ \\
Test nondominant hand time (s) & $94.31 \pm 43.27$ & $83.50(22.00-321.00)$ \\
Retest nondominant hand time (s) & $79.69 \pm 37.61$ & $73.00(22.00-235.00)$ \\
Test total raw score & $96.85 \pm 17.12$ & $94.00(67.00-165.00)$ \\
Retest total raw score & $101.07 \pm 26.38$ & $92.25(50.50-180.00)$ \\
Test weighted total accuracy score & $-0.53 \pm 0.50$ & \\
Retest weighted total accuracy score & $-0.32 \pm 0.60$ & \\
\hline
\end{tabular}

Table 2. MAc-R dominant-nondominant hand test-retest results

\begin{tabular}{lcc}
\hline & $\begin{array}{c}\text { MAc-R dominant hand } \\
\text { test-retest }\end{array}$ & $\begin{array}{c}\text { MAc-R nondominant } \\
\text { hand test-retest }\end{array}$ \\
\hline Test statistics $\left(\mathrm{Z}^{\mathrm{a}}\right)$ & -0.073 & -2.907 \\
$\mathrm{p}$ & 0.942 & $0.004^{*}$ \\
\hline
\end{tabular}

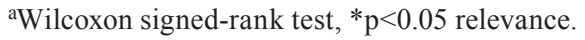

Table 3. DTVP-2 Eye-Hand Coordination Test findings

\begin{tabular}{lcc}
\hline & Average \pm SD & Median (min-max) \\
\hline DTVP-2 Eye-Hand Coordination Test & $157.51 \pm 6.66$ & $158.00(139.00-177.00)$ \\
\hline
\end{tabular}

Table 4. Test-retest measurements between ICC

\begin{tabular}{|c|c|c|c|c|}
\hline & & $\begin{array}{c}\text { MAc-R retest dominant } \\
\text { hand raw score }\end{array}$ & $\begin{array}{l}\text { MAc-R retest nondominant } \\
\text { hand raw score }\end{array}$ & $\begin{array}{c}\text { MAc-R retest total } \\
\text { raw score }\end{array}$ \\
\hline MAc-R test dominant hand & ICC & 0.745 & & \\
\hline raw score & $95 \% \mathrm{CI}$ & $0.621-0.828$ & & \\
\hline MAc-R test nondominant & ICC & & 0.819 & \\
\hline hand raw score & $95 \% \mathrm{CI}$ & & $0.731-0.878$ & \\
\hline MAc-R test total raw score & $\begin{array}{l}\mathrm{ICC} \\
95 \% \mathrm{CI}\end{array}$ & & & $\begin{array}{c}0.813 \\
0.722-0.874\end{array}$ \\
\hline
\end{tabular}

ICC: Intraclass Correlation Coefficient; CI: Confidence Interval.

As the validity and reliability were calculated, whether or not constant variables were distributed normally was investigated using the Shapiro-Wilk test and normal distributed variables were evaluated using the paired samples test and those that were distributed abnormally were evaluated via the Wilcoxon signed-rank test during the test-retest measurement comparisons. To identify the relevance, direction, and power of the relationship between two constant variables, Pearson's correlation coefficient was used when the data were distributed normally while Spearman's correlation coefficient was utilized when the data distribution was abnormal.

The Statistical Package for the Social Sciences Program (SPSS-20) was used for the analyses, and the confidence interval was $95 \%$. The analysis results were interpreted in comparison to the $\mathrm{p}<0.05$ level.

\section{RESULTS}

Of the 100 children who participated in this study, 51 were boys and 49 were girls. Overall, 90 children had a dominant right hand and 10 had a dominant left hand. The mean age was $7.16 \pm 0.6$ (range: $6.17-8.83$ ). The children's average height was $130.65 \pm 5.99 \mathrm{~cm}$. Their average weight was $28.82 \pm 6.62 \mathrm{~kg}$. The average RI was $12.83 \pm 2.18 \mathrm{~kg} / \mathrm{cm}^{3}$. (Rohrer index $=(\mathrm{kg} /$ $\left.\left.\mathrm{cm}^{3}\right) \times 10^{6}\right)^{25}$. The MAc-R test-retest findings are presented in Table 1. The test-retest results of the MAc-R dominant-nondominant hands are presented in Table 2. The DTVP Eye-Hand Coordination Test findings are shown in Table 3. The MAc-R test and the DTVP-2 Eye-Hand Coordination Test results can be found in Table 4. 


\section{DISCUSSION}

The reliability between the test-retest and the evaluations of each of SIPT's17 subtests were very high. The test-retest reliability of the MAc-R test was conducted with a group of 45 participants, and when calculated together with the weighted total accuracy score, the reliability was $\mathrm{r}=0.84^{1}$ ). The results of this study indicated that the MAc-R test is reliable and valid in Turkish children aged 6-8 years 11 months. In previous studies, the U.S. norms and the time identified according to the children from the U.S. were used to calculate the reliability evaluation weighted total accuracy scores. Taking into account that Turkish norms were identified, the relationship between both the weighted total accuracy scores' test-retest measurement results (ICC.785) (95\% CI 0.623-0.823) and the raw scores' test-retest measurement results (ICC $=.813)(95 \% \mathrm{CI}$ $0.722-0.874)$ were investigated in this study. Although the differences between the correlation coefficients obtained with the weighted total accuracy score of this study and the one conducted in the U.S. were high, this study's correlation coefficient obtained with the raw score was very close to that obtained with the weighted total accuracy score in the U.S. The closeness of the raw scores and the correlation coefficient obtained through the weighted total accuracy score in the U.S. to each other was linked to the creation of the weighted total accuracy score according to the U.S. norms and to the identification of the Turkish norms. It has been posited that it is necessary to identify the norm values and create evaluation criteria in Turkey.

In this study, the validity of the MAc-R was examined via comparison to the DTVP-2 eye-hand coordination test. In previous studies, the validity of the MAc-R test was assessed by examining its relationship with different tests (such as the Kaufman Assessment Battery for Children) and SIPT's other subtests (such as Design Copying) ${ }^{1)}$. The reason behind examining its relationship with other subtests is that the MAc-R test enables the evaluation of sensory integration and praxis through multi-directional evaluation. To the best of our knowledge, the relationship between the MAc-R test and the DTVP-2 Eye-Hand Coordination Test was not examined in previous studies. When Ayres' study conducted in 1966 was assessed, it was thought to be the relationship between the MAc-R test and the DTVP-2 Eye-Hand Coordination Test ${ }^{1,10)}$. Because the researcher had previously used the DTVP-2 Eye-Hand Coordination Test clinically, the validity-reliability of the DTVP-2 Eye-Hand Coordination Test was shown in Turkey ${ }^{26,27)}$ and it has been widely used. Both tests evaluate eye-hand coordination and were used in the same study by Ayres in 1965-1966 and it has been hypothesized that there is a relationship between them. The DTVP-2 Eye-Hand Coordination Test is used as a reference to identify the validity of the MAc-R test.

The validity evaluation in this study was conducted via raw scores to eliminate bias that might occur due to ignoring the time factor in the DTVP-2 Eye-Hand Coordination Test. Meaningful correlation was found between the DTVP-2 Eye-Hand Coordination Test and all measurements. All of the correlation coefficients were in the negative direction and at the middle level. As a result of the conformity analysis between the MAc-R test and the DTVP-2 Eye-Hand Coordination Test for validity, the correlation coefficient was negative $(\mathrm{r}=-0.531)$ and at the middle level $(\mathrm{p}<0.001)$.

Although the DTVP-2 Eye-Hand Coordination Test indicated the validity of SIPT's MAc-R, these two tests do not completely correspond to each other. While the DTVP-2 Eye-Hand Coordination Test includes only visual perception, eye-hand coordination, fine motor skills, and ocular tracking, the MAc-R test is more extensive with a broader evaluation area ${ }^{1)}$. The fact that the validity value was at the middle level in this study likely depended on this difference.

Among the children evaluated with the MAc-R test, those with the highest raw scores had the weakest eye-hand coordination. Among the children evaluated with the DTVP-2 Eye-Hand Coordination Test, those with the highest raw scores had the best eye-hand coordination. This means that to assess whether eye-hand coordination is good in a child evaluated with the MAc-R test and the DTVP-2 Eye-Hand Coordination Test, the MAc-R raw score must be low and the DTVP-2 Eye-Hand Coordination Test raw score must be high. Therefore, it was expected that the correlation coefficient found through the conformity analysis of these two tests would be in the negative direction.

The MAc-R test measures the visual, vestibular, somatosensory, and bilateral integration areas in addition to eye-hand coordination. In future studies to be conducted in Turkey, it will be important to examine the relationship between the MAc-R test and different tests related to each of its areas.

The strong aspects of this study include a sufficient number of cases and the fact that SIPT was conducted by an experienced physiotherapist trained in its terms of application. This study's limitations include that it was a single-center test, the standard values of the MAc-R test have not been identified in Turkey, Although the MAc-R test's validity and reliability have demonstrated in children aged 4 years to 8 years, 11 months, this study was conducted with children aged 6 years to 8 years, 11 months, because there are substantial differences between the levels of children aged 4 years to 8 years, 11 months. Prospectively, the validity and reliability of the MAc-R test should be indicated in children between the ages of 4 to 6 years in Turkey.

This study evaluated the validity and reliability of the MAc-R test in normal children. Identifying the validity and reliability of the MAc-R test in different diagnostic groups in future studies might provide guidance for clinical practice.

The literature indicates that the MAc-R test has been applied in normal schools and has identified children with sensory integration disorders that adversely affect their academic success ${ }^{1,5}$. By providing these children the necessary sensory integration training, their academic success improved. Turkish schoolchildren who require sensory integration training could be identified and provided with the training to promote their academic success.

Applying SIPT to children with sensory integration disorders is considered crucial to define their sensory integration 
disorders and provide therapy ${ }^{1)}$. It is believed that the MAc-R test, whose validity and reliability were demonstrated in Turkey, will play a crucial role in increasing success in special education and rehabilitation programs.

This study was conducted only on the MAc-R test. Considering that the interaction of SIPT"s 17 subtests together and with each other and the sensory integration have been evaluated separately, it is suggested to take into account in future studies the fact that the conduction of the validity and reliability studies of SIPT's other subtests in Turkey might be important.

As a result, it is believed that identifying the validity and reliability of the MAc- $R$ test in Turkey will have an important place in evaluating children's sensory integration in physiotherapy and rehabilitation practices.

\section{Funding}

This study was funded by Scientific Research Unit (Bilimsel Araştırma Projeleri) of Demiroglu Bilim University with the number 2016-0109, 2016.

\section{Conflict of interest}

The authors declare that there is no conflict of interest.

\section{REFERENCES}

1) Ayres A: Sensory integration and praxis tests, updated ed. (SIPT) [Manual]. Torrance: Western Psychological Services, 1989.

2) Bodison S, Mailloux Z: The sensory integration and praxis tests illuminating struggles and strengths in participation at school. OT Pract, 2006, 11: CE1-CE7.

3) Mailloux Z: An overview of the sensory integration and praxis tests. Am J Occup Ther, 1990, 44: 589-594. [Medline] [CrossRef]

4) Saeki K, Clark FA, Azen SP: Performance of Japanese and Japanese-American children on the motor accuracy-revised and design copying tests of the southern California sensory integration tests. Am J Occup Ther, 1985, 39: 103-109. [Medline] [CrossRef]

5) Schaaf RC, Mailloux Z: Clinician's guide for implementing Ayres sensory integration: Promoting participation for children with autism. Bethesda: AOTA Press. 2015.

6) Mailloux Z, Miller-Kuhaneck H: Evolution of a theory: how measurement has shaped Ayres Sensory Integration. Am J Occup Ther, 2014, 68: 495-499. [Medline] [CrossRef]

7) Mandell RJ, Nelson DL, Cermak SA: Differential laterality of hand function in right-handed and left-handed boys. Am J Occup Ther, 1984, 38: 114-120. [Medline] [CrossRef]

8) Smith SM: Performance difference between hands in children on the motor accuracy test-revised. Am J Occup Ther, 1983, 37: 96-101. [Medline] [CrossRef]

9) Asher AV, Parham LD, Knox S: Interrater reliability of Sensory Integration and Praxis Tests (SIPT) score interpretation. Am J Occup Ther, 2008 , 62: 308-319. [Medline] [CrossRef]

10) Ayres AJ, Reid W: The self-drawing as an expression of perceptual-motor dysfunction. Cortex, 1966, 2: 254-265. [CrossRef]

11) Mailloux Z, Mulligan S, Roley SS, et al.: Verification and clarification of patterns of sensory integrative dysfunction. Am J Occup Ther, 2011, 65: 143-151. [Medline] [CrossRef]

12) Mulligan S: Patterns of sensory integration dysfunction: a confirmatory factor analysis. AJOT, 1998, 52: 819-828. [CrossRef]

13) Roley SS, Mailloux Z, Parham LD, et al.: Sensory integration and praxis patterns in children with autism. AJOT, $2015,69$.

14) Van Jaarsveld A: Patterns of sensory integration dysfunction in children from South Africa. SAJOT, 2014, 44: 1-6.

15) Ayres AJ: Southern California motor accuracy test. Los Angeles: Western Psychological Services. 1964.

16) Ayres AJ: Southern California motor accuracy test-Revised. Los Angeles: Western Psychological Services. 1980.

17) Bumin G, Kayihan H: Effectiveness of two different sensory-integration programmes for children with spastic diplegic cerebral palsy. Disabil Rehabil, 2001, 23: 394-399. [Medline] [CrossRef]

18) Huri M, Gündüz F: Investigation of the effect of sense-based ergotherapy group intervention on the sensory modulation, postural praxis and bilateral motor coordination skills in gifted children: a pilot study. Ergoterapi Rehabil Derg, 2016, 4: 137-144.

19) Huri M, Şahin S, Kayıhan H: Investigation of hand function among children diagnosed with autism spectrum disorder with upper extremity trauma history. Ulus Travma Acil Cerrahi Derg, 2016, 22: 559-565. [Medline]

20) Huri M, Mehr BK, Altuntaş O, et al.: Comparison of tactile preferences of children with common developmental disorder and normal development. Ergoterapi Rehabil Derg, 2014, 2: 21-28.

21) Kayıhan H: A comparative study on the test and treatment of sensory-perception-motor integration function disorders in hemiplegia and cerebral paralysis. PhD Dissertation Thesis, Hacettepe University Social Science Institute, Ankara, 1986.

22) Frostig M, Lefever DW: A developmental test of visual perception for evaluating normal and neurologically handicapped children. Percept Mot Skills, 1961, 12: 383-394. [CrossRef]

23) Frostig M, Lefever DW, Whittlesey J: Administration and scoring manual for the Marianne Frostig Developmental test of visual perception. Palo Alto: Conculting Psychologist Press, 1966.

24) Maslow P, Frostig M, Lefever DW, et al.: The Marianne Frostig Developmental test of visual perception, 1963 Standardization. Percept Mot Skills, 1964, 19: 463-499. [Medline] [CrossRef]

25) Takasaki Y, Nakakura S, Anzai S: Preferable body build indices in children. J Anthrop Soc Nippon, 1987, 95: 487-496. [CrossRef]

26) Aral N, Bütün-Ayhan A: The adaptation of Frostig visual perception test to Turkish. JASSS, 2016, 50: 1-22.

27) Sökmen S: Age five perceptual development (Frostig Visual Perception Test Reliability Study). Master's Thesis, Marmara University Social Science Institute, İstanbul. 1994. 